\title{
CONTEMPORARY CHALLENGES IN MORAL AND LEGAL TREATMENT OF ANIMALS
}

\begin{abstract}
The purpose of the present paper is to demonstrate the inconsistencies between ethical theory and legal practice of animal treatment. Specifically, we discuss contemporary legal solutions, based on three case studies - Serbian, German and UK positive law, and point out the inconsistencies in them. Moreover, we show that the main cause of these inconsistencies is anthropocentric view of moral relevance. Finally, when it comes to the different treatment of animals living in the wild and domestic animals, we show that the current theoretical explanations are unsatisfactory.
\end{abstract}

Keywords: Animal rights, animal welfare, anthropocentrism, duties, positive law.

\section{Introduction}

Compared to the frequency of dilemmas concerning the treatment of animals in everyday life, the question of the moral status of animals has considerably been neglected in philosophical literature. Korsgaard (2011) points out that ethical decisions on how to treat animals are made on a daily basis, whereas the moral dilemmas discussed in depth in literature, such as sacrificing an innocent person for the well-being of others, are situations which occur rarely (or never) in an average human life-span. Also, positive laws in a growing number of countries require protection of an animal's well-being. The scope of these laws can be very wide and can provide an array of duties that humans have towards animals. For instance, positive laws that guarantee the well-being of animals, prohibit torture, neglect, and abandonment of animals, etc. ${ }^{1}$ In section 3 , we will discuss in more detail particular legal solutions and present what we believe to be their correct ethical justification. The third reason why this topic deserves philosophical analysis and debate is an obvious one: we have strong intuitions and feelings concerning animal protection and welfare provision. In particular, because of these intuitions and feelings we are faced with everyday dilemmas with respect to the treatment of animals. It is precisely because of these intuitions and feelings that the number of organisations protecting and

1 E.g. the Animal Welfare Act 2006 of the United Kingdom, the German Animal Welfare Act 1998, the Animal Welfare Act of the Republic of Serbia 2009. 
advocating animal welfare and rights has been growing, and in the final instance positive laws have been brought.

The importance of philosophical analysis and ethical grounding lies in making a coherent and justifiable framework for human actions and should serve as a basis for the further development of animal-human interaction. Having in mind both the frequency of ethical dilemmas concerning human treatment of animals and the legal relevance of this subject, we conclude that a serious philosophical analysis is timely. The aim of the present paper is to (1) draw attention to the debate surrounding the moral status of animals, (2) point out and underline certain aspects of the debate, i.e. discrepancies among our intuitions, positive law, and main ethical approaches, and (3) provide some directions that might be helpful in addressing this issue.

In the rest of this section, we will briefly reflect upon the treatment of animals in the Western philosophical tradition. In the next section, we will explain the methodology employed in our paper and its organization. However, we would firstly like to advocate for a small, yet important shift in terminology. We do not refer to an animal as an "it". We believe that once animals are granted moral status, they should not be referred to as objects." In the history of philosophy, there have been many examples of denying the moral status to animals. Some philosophers, like René Descartes (1989) and Immanuel Kant (1997) were reluctant to grant the moral status to animals, because they lack the typically human characteristics such as rationality, consciousness, or autonomy. Others denied the moral standing of animals on the ground of their religious or philosophical views according to which animals are inferior to human beings and exist to serve them. One of the earliest expressions of this view can be found in Aristotle, and afterwards in the Christian philosophical tradition (see Balme 1991). Some of these approaches consider harming animals as morally detrimental in an indirect fashion, only if it has a negative influence on the treatment of humans. Animals are treated as mere objects or instruments for satisfying human goals. This kind of an approach is an unquestionable example of anthropocentrism.

One of the famous positive examples in the history of philosophy before the twentieth century is Jeremy Bentham (2007) who thought that moral considerability of animals is grounded in their sentience, i.e. their capacity to experience pleasure and pain. In the second half of the twentieth century, things started to change for the better, philosophers began to question such a simplified picture of morality in which there is no place for anyone but humans, and which does not incorporate and explain the complexity of human interaction with other species. We can distinguish three major theoretical approaches that recognise the moral significance of non-human animals: the animal welfare approach, the animal rights approach, and the environmental ethics approach. The animal welfare approach, whose most prominent defender is Peter Singer, is essentially utilitarian. According to this approach, equal interests of all sentient beings must be taken into account equally in the utilitarian calculus. This means that human interests do not have primacy over the interests of members of any 
other species just because they are human interests. However, in accordance with utilitarian logic, interests of animals can be outweighed by the aggregate interests of others (see Singer 1976). The animal rights approach, unlike the animal welfare approach with which it is often confused, has a significant deontological component. This means that there is a privileged group of beings (something like Kant's Kingdom of Ends) who possess rights that cannot be overpowered by the aggregate interests of other beings. The criterion for membership in this group is subjecthood i.e. the capacity to have propositional attitudes, emotions, self-consciousness, and awareness of the future. Every member of this group is entitled to unconditional protection of her basic interests, such as the right to life and integrity of consciousness and activity, which includes freedom to exercise the specific capabilities of a species (see e.g. Regan 1983). It is very important to understand the difference between the animal welfare and the animal rights position. The first position allows sacrificing important interests of animals, even their lives, to advance the overall well-being of other sentient beings, while the second never allows sacrificing animal rights, nor using animals as a mere means to an end, no matter how important the end itself is. Lastly, the environmental ethics approach is holistic, it places value on a live natural aggregate - a species, or on a live natural system - an ecosystem, or on the whole biosphere. From this position an individual animal is not important except for her role in the larger unit. It is considered to be justified to kill an individual or some larger number of individuals if that will contribute to the preservation of diversity within the biosphere (see Brennan and Lo 2011).

\section{The methodological approach and the division of labour}

The problem with the theoretical treatment of the moral status of animals is that we lack adequate moral concepts for analysing it. Our moral concepts are designed primarily for human animals. Non-human animals in some sense exist on the margins of our current theoretical moral framework. Everyday treatment of animals is not grounded on a coherent theoretical framework but on feelings, intuitions, and pragmatic considerations. We do not want to deny the importance of these feelings, intuitions, and pragmatic considerations; on the contrary, we want to emphasise the importance of developing a theoretical approach that takes them seriously and gives consistent theoretical solutions based on them.

We provide an overview of the debate surrounding the question of the contemporary moral status of animals focusing on the discrepancy among ethical theory, actual legal practice, and our intuitions. First, in section 3 we turn to the existing positive laws and show that they are mainly grounded on the animal welfare approach, i.e. utilitarianism. Therefore, in section 4, we raise questions that we believe to be problematic for utilitarianism as the potential ground for the moral relevance of animals. Namely, we show that any anthropocentric criterion including the feeling of (human-type) pain is arbitrary as a ground for the moral relevance of animals. Further on, we notice that not only is there a significant difference in the treatment of pets in opposition to other domestic animals, but 
there is also a big distinction in the legal and theoretical treatment of animals in human society and animals living in the wild. In section 5 , we present a solution proposed by Elisabeth Anderson (2004) that emphasises precisely this social dimension. However, it is questionable whether this discrepancy in treatment is coherently grounded. In the end, we believe that it is safe to conclude that the current grounding of the moral treatment of animals is unsatisfactory and that an adequate one would need to answer all the questions raised in this paper, as explained in the concluding section.

\section{The analysis of existing laws}

Clearly, the existing laws rely mainly on the animal welfare approach, i.e. utilitarianism. This can be seen because of the emphasis given to the fact that animals are capable of experiencing pain or suffering. ${ }^{2}$ Furthermore, animals are protected from unnecessary harm, i.e. "no one may cause an animal pain, suffering or harm without good reason" as stated in the German Animal Welfare Act from 1998, article 1. This leaves room for exposing animals to suffering for the "greater good", for instance, particular types of medical testing, which is precisely the moderate position of the animal welfare approach. On the other hand, the animal rights approach would not allow for such exceptions. According to the animal rights approach, a right granted to an animal or species needs to be universal in the same way as human rights are. Such a right can only be overpowered by the right of another individual, for instance, harming someone in self-defence. Since people seem to be reluctant to give up animal testing and the like that result from human primacy over animals, they are equally reluctant to grant full rights to animals.

According to utilitarianism, duties towards animals are based on the fact that animals are sentient i.e. capable of experiencing pleasure and pain. In this sense animals are bare moral patients. However, we wonder whether there are reasons to grant animals a stronger moral status. For example, the fact that animals in some situations protect and help us and each other might be one of the reasons. Mark Rowlands (2012) argued that "animals can act morally in the sense that they can act on the basis of moral emotions - emotions that possess identifiable moral content" (p. 15). According to Rowlands, animals are not bare moral patients, nor moral agents, but they are moral subjects, since they sometimes act upon moral emotions, such as tolerance, compassion, empathy, etc. On the other hand, since they are not moral agents they cannot be held responsible for their actions.

Another important note about the contemporary positive law is the fact that humans are obliged not only not to harm animals, but also to provide for their welfare. For instance, according to the Animal Welfare Act 2006 of the United Kingdom, article 9.2, humans responsible for an animal have legal duty to provide a suitable environment, diet for the animal, protect her from

2 E.g. in the Animal Welfare Act 2006 of the United Kingdom, article 4. 
pain, injuries, diseases, etc. The theoretical grounding of such positive rights for animals is challenging. In section 4, we present Elisabeth Anderson's (2004) position that provides significant support for positive rights towards domestic animals and captives from the wild. Also, it is questionable whether the very distinction between positive and negative rights and respective duties is actually meaningful and informative. We turn to this in sections 6 .

Though mainly based on utilitarianism, the positive legal solutions are not consistently utilitarian. When it comes to the regulations of hunting, the logic of the ecological approach is used in the sense that the hunt is allowed as long as it does not endanger the survival of the species, e.g. the Law on Venison and Hunting of the Republic of Serbia, 2010, article 2. Clearly, this legal solution gives primacy to the species over an individual animal and is therefore in line with the ecological approach. Utilitarianism, on the other hand, does not recognise populations, species and ecosystem as morally relevant entities. What utilitarianism and ecological approach have in common is the fact that an individual can be sacrificed for the "greater good", i.e. for the good of a group. However, justifications for these sacrifices are different. Ecological ethics approach advocates for controlling the population of wild animals by hunting them down or even by biological war, e.g. by deliberately infecting a population with a virus with the goal of radically reducing it (Berber \& Sikimić 2016). For a utilitarian it is inacceptable to scarifies an animal only for the reasons of population control. A consistent utilitarian needs to perform a complex utilitarian calculus before making a decision to sacrifice any individual.

Moreover, there is a difference in the legal treatment of pets and animals kept in zoological gardens and other domestic animals, or captives from the wild used in experiments. According to the Animal Welfare Act of the Republic of Serbia 2009, article 15, killing pets and animals kept in zoological gardens is forbidden, unless in the case of serious illness. Other domestic animals, as well as captives from the wild used in experiments, can be killed. It is not clear which ethical criterion can explain why a pig bought in the pet shop should be treated differently than the one living on a farm.

All things considered, utilitarianism as the dominant and rather coherent doctrine cannot be dismissed easily when it comes to grounding of the animal welfare acts. Utilitarian grounding of the moral treatment of animals is based on the fact that animals, express pain and pleasure in a similar fashion as humans do. In such a justification we see that animals have moral status guaranteed because they are recognised as similar to humans. Such an anthropocentric picture might lead to the conclusion that animals who do not have either humanlike demonstrations of pain and pleasure, or the physiology that is similar to the human one, should enjoy weaker moral status. This problem is the most evident when it comes to psychological and emotional pain and pleasure. We might not always be able to identify the pain and the pleasure of a being with the psychology and emotional structure radially different from ours. Thus one of our main concerns when it comes to the utilitarian criterion is that its implementation leaves room for arbitrariness and anthropocentrism. In the 
next section, we turn to anthropocentrism as a possible ground for the moral treatment of animals and criticise it.

\section{Is anthropocentrism arbitrary?}

Questions such as whether animals are like us, in which respect they are like us, and to which extent they are like us, are often in focus of the debates on the moral status of animals. Taking similarity to human beings as the only or main criterion of the moral value of a being is what is usually called "anthropocentrism". There are several problems with anthropocentrism that we want to underline. Firstly, individual capacities of a being are not the only source of moral duties towards her. This point is strongly supported by the socalled argument of marginal cases. According to the argument of marginal case, whenever one tries to justify asymmetry in treatment between human and nonhuman animals based on some trait or collection of traits that humans possess, it will be possible to point out to a human lucking this trait or the collection of traits. For instance, if one wants to claim that humans should have special moral status based on their cognitive abilities, we can point out to human beings who for some reason do not have the common human cognitive abilities, for example, the mentally challenged or people suffering from dementia, and towards whom we nevertheless have duties (Anderson 2004). Thus, the argument of marginal cases is based on the difficulty of finding a relevant characteristic or collection of them that captures all and only humans. Secondly, we should ask ourselves what would justify taking similarity to human beings as the criterion of moral value. The inclination to be more compassionate towards beings who are similar to us may be natural, but we cannot take this psychological tendency as the only source of moral value without a justification. Even if we presuppose that humans are superior to all other species, this does not entail that other species do not have a moral value of their own. More importantly, we hold that it is mischievous to think in categories of superiority and inferiority in this context. On the other hand, if we dismiss any anthropocentrism, it is not clear what we should take as the criterion for evaluation of non-human life. The ecological approach grants certain rights to all the living species, however, it still uses a (terrestrial) biological definition of life. An approach based on pure intelligence of an individual could grant moral status to non-biological individuals in the terrestrial sense, however, the question is whether humans are in principle able to comprehend and acknowledge intelligent forms that are potentially radically different than ours.

Note that like utilitarianism, the animal rights approach is also based on anthropocentric criteria, but these criteria focus on the cognitive capacity of an animal. The animal rights approach favours animals that have similar cognitive capacities to human ones.

The fundamental question concerning anthropocentrism, granted the basic assumption that similarity to humans is crucial for determining the moral 
status of a being, is what kind of similarity is more important: an emotional or a cognitive one. We can imagine that there are beings (extra-terrestrials or ones with artificial intelligence) who are hyper rational, but are not able to experience pleasure and pain. The question is whether such hypothetical beings would have any duties towards humans and whether humans would have any duties towards them.

Utilitarianism gives a moral status to all beings who are capable of experiencing human-like pain and pleasure. According to utilitarianism, humans need to guarantee welfare to an animal, or any other being with the above characteristics, even if some of them are incapable of acting reciprocally (i.e. they are mere moral patients). Now a serious question arises: would a hypothetical hyper rational being with no emotions need to have any duties (positive or negative) towards other (less rational) beings, and why?

If the utilitarian maxim aspires to be the unique and universal moral ground, it seems that according to utilitarianism purely rational beings that do not experience pleasure or pain in a human-like fashion, would need to treat all sentient beings morally, but would not need to treat each other in such a manner. Moreover, none of the purely rational beings would be a moral patient. Thus, rationality would need to give primacy to sentience, and that is highly counterintuitive. It is unclear whether purely rational beings could have their own morality based on rationality and even grant humans some moral rights, but at same time humans would not treat them as moral patients in return. They would represent a specific type of moral agents who are not moral patients. It is also unclear why such rational beings would accept that sentient beings count more in the utilitarian calculus than they do themselves, especially if they are incapable of feeling any empathy.

MacDonald Glenn (2002) offered a system that can incorporate both moral treatment of animals and of artificial intelligence. She claims that the notion of personhood cannot be defined in an absolute manner. According to this approach, each individual enjoys legal rights based on the set of traits she possesses, while she does not enjoy rights related to the set of traits she lacks. For instance, minor children do not have the right to vote, but enjoy a whole array of other rights. In this fashion, some legal rights can be granted also to artificially intelligent beings, e.g. the right not to be destroyed. Her approach offers a basis for changing the legal norms. It is important to develop an approach in ethics that could treat both animals and artificial intelligence; the position of MacDonald Glenn is a promising starting point for a comprehensive theory. We would like to point out that a candidate for such a criterion with a stronger philosophical component could be based on the family resemblance in the sense of late Wittgenstein (1986). In particular, animals share a set of traits with humans that make them morally relevant and the potential artificial intelligence might share a set of traits with humans that make them morally relevant. However, these two sets do not need to coincide. Lastly, it is conceptually possible that there are some properties that make an individual morally relevant, but that humans do 
not posses them, though humans certainly posses other properties which make them morally relevant.

Still, all this does not mean that the utilitarian hypothesis which claims that beings who experience pain need to be treated as moral patients, and therefore be granted certain. moral status, should be dismissed. It rather means that such a justification is insufficient to capture the phenomenon and cannot be accepted as the unique and universal moral principle, though it is very useful in capturing certain aspects of our ethical considerations. Apart from the problem of the different treatment between pets and domestic animals used for farming, the discrepancy in the treatment of animals is most prominent when it comes to the differences between the treatment of animals living in human society and the ones living in the wild. Clearly, the utilitarian criterion is not sufficient to justify these differences. In the next section, we turn to the problem of justification of the difference in the treatment between domestic and wild animals.

\section{Domestic and wild animals}

Elizabeth Anderson (2004) connects right to provision with membership in society, because, as she argues, only social membership can vindicate individual moral right to provision by specifying who has the obligation to provide the necessities of life to which individual. Human beings are automatically included into human society. However, two other classes of animals have also been incorporated into human society - domesticated animals and captives from the wild, which means that animals from these classes also have right to provision. According to Anderson, individual animals living in the wild, in general, do not have the right to our protection or provision even in case they need it for survival. We think that Anderson's position has a certain intuitive plausibility. It is true that we have a larger list of obligations towards domestic animals than towards those living in the wild. Nevertheless, we want to draw attention to some principal difficulties concerning this position. First, Anderson's position is related to the suspicious distinction between positive and negative rights. The usual explanation is that positive rights are the ones that oblige an action, while negative rights are the ones that oblige an inaction. In the next section we refer to the problems of this distinction. Second, we are not confident that we never have a duty to help a wild animal. What if some wild species or individual is endangered due to human activity, for instance, pollution or destruction of the animals' natural habitat? In that case, it is not justified to say that our only duty towards wild animals is to let them be. Humans at least have a positive duty to compensate for the damage they have caused.

We agree with Anderson that animals are not in a position to protect their well-being inside the human society in an adequate manner and therefore humans are obliged to help them do so. For instance, some positive laws, such as the Animal Welfare Act of the Republic of Serbia 2009, article 3.4, demand reporting animal abuse and neglect, precisely because the animal is not capable of 
filing such a report herself. However, we question the position that wild animals are never entitled to our protection and help. Besides the intuition that we have impulse to help an animal in need, even if she is living in the wild, and the fact that some wild animals behave protectively towards humans, e.g. dolphins, if the distinction between positive and negative duties is dismissed, it becomes arbitrary which class of duties one has towards different types of animals. The same objection can be raised against the approach developed by Donaldson and Kymlicka (2011). On the positive side, in addition to explaining the difference in the treatment between the animals that are part of human society and the animals living in the wild, they introduce a specific category of the animals who live at the margins of human communities and are not completely independent of them, such as foxes and racoons. According to this approach, the animals living in the wild enjoy a certain type of sovereignty, which means that humans are not allowed to endanger their habitats. Still, it remains unclear how much humans are allowed to interfere in the wild life in order to help or protect the animals living in the wild. Moreover, humans already indirectly affect the whole biosphere, e.g. by pollution and global warming. ${ }^{3}$

\section{Wild life and positive duties}

We will only tackle the big discussion on the distinction between positive and negative duties in order to demonstrate that it is not as unproblematic as it may prima facie seem. If this distinction is dismissed, then obviously there is no ground for the different treatment of animals living in human society (domesticated animals and captives from the wild) and animals living in the wild based on it. In the case of domestic animals, as already mentioned, both positive and negative duties are covered by positive laws granting their well-being. For instance, the domestic animal is entitled to proper treatment in the sense that she should not be neglected, nor abandoned. However, only the "negative" rights are assigned towards the great apes living in the wild, such as the right not to be killed. ${ }^{4}$ Positive law also forbids for a wild animal that has grown up or spent significant time in captivity to be returned into the wilderness without special preparation that will guarantee successful integration of the animal in the new environment, e.g. the German Animal Welfare Act from 1998, article 3.

The intuitive ethical grounding that Anderson (2004) provides states that domestic animals and captives from the wild, enjoy positive rights, while animals living in the wild only enjoy negative rights. The social dimension brought up by Anderson additionally emphasises our responsibility towards animals incorporated into human society. However, we are still responsible for our environment. There is also no clear-cut differentiation between parts of the environment that are affected by humans in direct or indirect way, e.g. global warming and parts that are not. Therefore, it is unclear how much humans

3 For more criticism of Donaldson's and Kymlicka's (2011) approach, see Cochrane (2013).

4 For more details about granting basic rights to the great apes, see Singer (2006). 
affect all of the wild animal habitats and what their corresponding responsibility towards the animals living in the wild is. On the other hand, our duties towards wild animals are also connected to the question of whether there is actually a big difference between positive and negative duties.

As intuitive as it may sound, it is questionable whether this distinction is real in the sense that it is meaningful and informative. Trivially, any law can be stated both in a negative and in a positive form. This is a fact granted by logic. For instance, the paradigmatic negative duty "do not kill" can be transformed into "let everyone live". Also, one famous positive duty "help others in need" can be transformed into "do not abandon others in need". Obviously, this is not a sufficient reason to reject the distinction as meaningless. One needs to consider the understanding of the action/inaction distinction. What we can conclude from the argument above is that, in formal terms, every "inaction" can be seen as a type of "action" and vice versa. Another line of argumentation claims that the distinction is not just unjustified but even harmful. For instance, Shue (1980, ch. 1-2) argued that the distinction between negative and positive rights can be harmful, because none of the necessary duties should be neglected. Moreover, this is in line with Kant's theory. Even though Kant's (2003) distinction between perfect and imperfect duties is considered to be the ground for differentiation between positive and negative rights, it is of crucial importance to keep in mind that all the duties are binding for him. This means that both type of duties are "the first class citizens" of Kant's moral architecture and it is unclear why one should have only one type of duty towards specific individuals. ${ }^{5}$

In a nutshell, the question of the moral status of non-human animals living in the wild is a difficult one. The main question within this debate is whether we have both positive and negative duties towards animals living in the wild. The advocates of the ecological approach desire that humans help all species in the ecosystem and assign them moral value based on the diversity of the biosphere. However, it is questionable whether the diversity of the biosphere can serve as an ethical ground. Moreover, if one wants to consistently apply the environmental approach, she would need to apply it also to human species. Clearly, humans are the ones that very much endanger the ecosystem. Yet, the principle of exterminating humans when they endanger other species or the ecosystem does not seem appealing. One the other hand, if we accept that humans only have moral responsibility for animals whose lives they have affected, it is hard to establish whether there is any large part of nature left intact and uninfluenced by humans directly or indirectly. If one accepts the idea that there are animals living in the wild that are not affected by humans, we would still feel the urge to help them if they are thirsty or badly injured,

5 The prefect duties are the one for which it is logically impossible to be universalized, while for the imperfect duties this is practically impossible. For more details, see Babić 1991. 
and it is still questionable whether such behaviour on our part is only based on our good will, i.e. whether it is morally neutral or actually morally required. Such a requirement would mean allowing positive duties towards wild animals. Lastly, if there are reasons for questioning the very distinction between positive and negative duties, it becomes unclear how to ground and justify restricted rights for wild animals.

\section{Concluding remarks}

In this paper, we have drawn attention to the question of the moral status of animals, provided an overview of the debate, and underlined certain aspects of it, which we believe to have been inadequately treated so far. Our main focus were inconsistencies of contemporary legal solutions w.r.t. ethical grounding. Finally, we have provided some guidelines that might be helpful in addressing these inadequacies.

The question of treating animals is a prominent question in our daily lives and as such deserves an appropriate theoretical analysis. We have analysed the question of the moral status of animals focusing on the two main alternatives, the utilitarian, i.e. the animal welfare approach, and the animal rights approach. We have pointed out that both of these approaches base the moral treatment of animals on anthropocentric criteria. However, when it comes to determining the set of morally relevant individuals, it is not clear what an alternative to anthropocentrism would be. Also, we demonstrated that certain positive laws (three case studies) appeal to utilitarian principles. Then we turned to the particular theoretical solutions that base the moral treatment of animals on duties and membership in human society. The main problem with these solutions is that they advocate different duties towards animals living in the wild and animals living in human society. We argued that this difference in treatment is not well founded. In the end, we believe that it is safe to conclude that the current grounding of the moral treatment of animals is unsatisfactory and that it is timely to provide answers to the questions raised in this paper.

Besides the distinction between animals living in the wild and the ones living in human society, the following categories of animals that are incorporated in human society can be listed: pets, captives from the wild, domestic animals in the strict sense, animals used for experiments, military purposes, etc. The question is how to justify the difference in treatment of these distinct categories inside human society. It would be beneficial to provide non-arbitrary criteria for treatment of all animals. However, the question of the moral status of animals cannot be answered in isolation, therefore it is important to first provide answers to fundamental ethical questions such as the grounding of moral principles on rationality, emotions or their combination, the question of the meaningfulness of the distinction between positive and negative duties, etc. 


\section{References}

Anderson, Elizabeth. 2004. "Animal Rights and the Values of Nonhuman Life." In Animal Rights: Current Debates and New Directions, edited by Cass R. Sunstein and Martha C. Nussbaum, 277-298. Oxford: Oxford University Press).

Balme, D. M. 1991. Aristotle: History of Animals, Books VII-X. Cambridge, MA: Harvard University Press.

Bentham, Jeremy. 2007. An Introduction to the Principles of Morals and Legislation. New York: Dover Publications.

Berber, Andrea, and Vlasta Sikimić. 2015. "The Moral Status of Animals." Collected Papers of the International Philosophical School Felix Romuliana 2008-2015, edited by Slobodan Divjak and Jovan Babić, 479-485. Zaječar: Center for Culture and Tourism [in Serbian].

Brennan, Andrew, and Yeuk-Sze Lo. 2011. "Environmental Ethics." In The Stanford Encyclopedia of Philosophy (Fall 2011 Edition), edited by Edward N. Zalta. Stanford: Metaphysics Research Lab, Center for the Study of Language and Information, Stanford University. http://plato.stanford.edu/archives/ fall2011/entries/ethics-environmental

Cochrane, Alasdair. 2013. "Cosmozoopolis: The Case Against GroupDifferentiated Animal Rights." Law, Ethics and Philosophy 1: 127-141.

Descartes, René. 1989. "Animals are Machines." In Animal Rights and Human Obligations, edited by Tom Regan and Peter Singer, 60-86. Englewood Cliffs, NJ: Prentice Hall.

Donaldson, Sue, and Will Kymlicka. 2011. Zoopolis: A Political Theory of Animal Rights. Oxford: Oxford University Press.

Kant, Immanuel. 1997. Lectures on Ethics. Cambridge: Cambridge University Press.

Kant, Immanuel. 2003. Groundwork for the Metaphysics of Morals. Translated and edited by Thomas E. Hill Jr. and Arnulf Zweig. Oxford: Oxford University Press.

Korsgaard, Christine M. 2011. "Facing the Animal You See in the Mirror." The Harvard Review of Philosophy 16(1): 4-9. doi: 10.5840/harvardreview20091611

MacDonald Glenn, Linda. 2003. "Biotechnology at the Margins of Personhood: An Evolving Legal Paradigm." Journal of Evolution and Technology 13. http:// jetpress.org/volume13/glenn.html

Regan, Tom. 1983. The Case for Animal Rights. Berkley: University of California Press.

Rowlands, Mark. 2012. Can Animals Be Moral? Oxford: Oxford University Press. Wittgenstein, Ludwig. 1986. Philosophical Investigations. Oxford: Basil Blackwell Ltd.

Shue, Henry. 1980. Basic Rights: Subsistence, Affluence, and U.S. Foreign Policy. Princeton: Princeton University Press. 
Singer, Peter. 1989. "All Animals are Equal." In Animal Rights and Human Obligations, edited by Tom Regan and Peter Singer, 148-162. Englewood Cliffs, NJ: Prentice-Hall.

Singer, Peter. 2006. “The Great Ape Debate." Project Syndicate, May 16. URL = $<$ http://www.project-syndicate.org/commentary/the-great-ape-debate> Laws

Animal Welfare Act. Federal Law Gazette I (p. 1094), Germany, 1998.

Animal Welfare Act. Official Gazette of the Republic of Serbia, no. 41/2009.

Animal Welfare Act 2006 (c. 45). UK Public General Acts, 2006.

Law on Venison and Hunting. Official Gazette of the Republic of Serbia, No. $18 / 2010$. 